\title{
Publisher Correction to: SDGs mainstreaming at the local level: case studies from Japan
}

\author{
Hiromi Masuda ${ }^{1,2}$ D $\cdot$ Mahesti Okitasari ${ }^{2} \cdot K$ anako Morita ${ }^{2,3} \cdot$ Tarek Katramiz $^{2,4} \cdot$ Hitomi Shimizu $^{4} \cdot$ Shun Kawakubo $^{1}$. \\ Yatsuka Kataoka ${ }^{5}$
}

Published online: 17 July 2021

(c) The Author(s) 2021

\section{Publisher Correction to: Sustainability Science https://doi.org/10.1007/s1 1625-021-00977-0}

The original version of the article has a number of corrections due to typesetting errors and corrected in this version.

Under the section "Analysis of SDGs mainstreaming in two "SDGs Future Cities"”, the sentence "The following sections', as these section numbers are gone when reflected in the journal format present a comparative analysis of the results for each category shown in Tables 4 and 5..." should have read as "The following sections present a comparative analysis of the results for each category shown in Tables 4 and $5 \ldots .$.

In Table 5 of this article, some texts were published incorrectly under the columns Kitakyushu (city), Shimokawa (town) and corrections are listed below.

- The text in the column "Kitakyushu (city)" headed 1.2 Political leadership, the following sentence "the SDGs

The original article can be found online at https://doi.org/10.1007/ s11625-021-00977-0.

Hiromi Masuda

hiromi.masuda.4z@stu.hosei.ac.jp

1 Hosei University, 2-33, Ichigayatamachi, Shinjuku, Tokyo 162-0843, Japan

2 United Nations University Institute for the Advanced Study of Sustainability (UNU-IAS), 5-53-70 Jingumae, Shibuya-ku, Tokyo 150-8925, Japan

3 Forestry and Forest Products Research Institute, 1 Matsunosato, Tsukuba, Ibaraki 305-8687, Japan

4 Keio University, 5322 Endo, Fujisawa, Kanagawa 252-0882, Japan

5 Institute for Global Environmental Strategies (IGES), 2108-11, Kamiyamaguchi, Hayama, Kanagawa 240-0115, Japan for Regional Revitalization Public-Private Partnership Platform)" should have read as “"'the SDGs for Regional Revitalization Public-Private Partnership Platform").

- The text in the column "Shimokawa (town)" headed 2.5 Vertical institutional coordination, the following sentence "the localization of SDGs" should have read as "the localization of the SDGs".

- The text in the column "Shimokawa (town)" headed 2.2 Multi-stakeholder involvement in project implementation, the following sentence "The Centre is planning to proactively develop', since the activity of Partnership Centre is still under development partnerships with stakeholders," should have read as "The Centre is planning to proactively develop partnerships with stakeholders,".

- The text in the column "Kitakyushu (city)" headed 2.5 Local governments engage in awareness raising and outreach activities, the following sentence "...participate in activities to promote SDGs" should have read as "... participate in activities to promote the SDGs".

- The text in the column "Shimokawa (town)" headed 2.5 Local governments engage in awareness raising and outreach activities, the following sentence "A treasure hunt focusing thematically on SDGs..." should have read as "... A treasure hunt focusing thematically on the SDGs...".

Under the section, "Availing of existing policy resources linked to formal procedures", on second paragraph, the following sentence “...Shimokawa's government applied the existing ordinance and Comprehensive Plan and the monitoring and review system to accommodate the SDGs,..." should have read "... Shimokawa's government applied the existing ordinance and Comprehensive Plan and the monitoring and review system to accommodate the SDGs....".

The reference of International Council for Science (2017) contains the word "Doi" incorrectly. The correct reference should read as "International Council for Science (2017) 
A guide to SDG interactions: from science. https://council. science/wp-content/uploads/2017/05/SDGs-Guide-to-Inter actions.pdf".

In addition, the reference "Lafferty W (2003)" should have read "Lafferty W, Hovden E (2003)". The correct reference should read "Lafferty W, Hovden E (2003) Environmental policy integration: towards an analytical framework. Environ Polit 12:1-22. https://doi.org/10.1080/0964401041 2331308254

The reference Oosterhof P (2018) has to be relocated in the alphabetical and it is corrected in original version of the article.

Finally, the reference Shimokawa Town Government (2018c) have processed with some spacing issue and it has been corrected.

The original article was updated.
Open Access This article is licensed under a Creative Commons Attribution 4.0 International License, which permits use, sharing, adaptation, distribution and reproduction in any medium or format, as long as you give appropriate credit to the original author(s) and the source, provide a link to the Creative Commons licence, and indicate if changes were made. The images or other third party material in this article are included in the article's Creative Commons licence, unless indicated otherwise in a credit line to the material. If material is not included in the article's Creative Commons licence and your intended use is not permitted by statutory regulation or exceeds the permitted use, you will need to obtain permission directly from the copyright holder. To view a copy of this licence, visit http://creativecommons.org/licenses/by/4.0/.

Publisher's Note Springer Nature remains neutral with regard to jurisdictional claims in published maps and institutional affiliations. 